\title{
Kinetics and Mechanism for Adsorption of Lead in Aqueous and Industrial Effluent from Pongamia pinnata Tree Bark
}

\author{
M.Mamatha ${ }^{1}$, H.B.Aravinda ${ }^{2}$, S.Manjappa ${ }^{3}$, E.T.Puttaiah ${ }^{4}$ \\ ${ }^{I}$ (Department of Chemical Engineering, Bapuji Institute of Engineering and Technology, Davangere, India) \\ ${ }^{2}$ (Department of Civil Engineering, Bapuji Institute of Engineering and Technology, Davangere, India) \\ ${ }_{3}^{3}$ (Department of Chemistry, Bapuji Institute of Engineering and Technology, Davangere, India) \\ ${ }^{4}(V C$, Gulbarga University, Gulbarga, India)
}

\begin{abstract}
Presence of heavy metals in water bodies due to industrialization has led to serious health problems. In the present study, an adsorbent prepared from the raw bark of the Pongamia pinnata tree was used for the removal of Lead from aqueous and waste water containing heavy metals. The effectiveness of this adsorbent was studied in batch studies for various size fractions of adsorbent at different $\mathrm{pH}$, concentration of metal ion, amount of adsorbent, contact time, agitation and temperature. The pseudo-first-order, pseudo-second-order and Elovich models were applied to test the kinetic experimental data. Pseudo second order model best fitted the adsorption of Lead ions. The Langmuir and Freundlich adsorption isotherm models were applied for the results. The Langmuir isotherms were best fitted by the equilibrium data. The maximum adsorption was found to be $34.36 \mathrm{mg} / \mathrm{g}$ in waste water at a temperature of $30^{\circ} \mathrm{C}$.
\end{abstract}

Keywords - Adsorption, Adsorption isotherms, Heavy metals, Industrial effluents, Lead

\section{INTRODUCTION}

Rapid growth in the manufacturing sector for the varieties of products and newer processes in the last few decades is the major cause for environmental pollution. Water bodies are polluted to different extent by a number of heavy metals. The heavy metals present in waste water streams are not degradable and at times are taken up by plants.[1] Industrial activities such as electroplating, tanneries, metallurgical, mining, textile, painting, car-radiator manufacturing etc., [2]-[3] generates various heavy metals in the effluent. Stringent regulations are made by various countries for proper disposal of these effluents [4].

Conventional physical, chemical and biological methods such as chemical precipitation [5], electrode deposition [6], membrane separations [7], evaporation, solvent extraction, ion exchange [2], [8], coagulation, cementation, biological treatment, reverse osmosis [9], accumulation by aquatic macrophytes [10] etc are available. As these methods have the problem of precipitate formation during treatment which in turn ends up with disposal problems they are not economically viable. In this regard adsorption is one of the promising methods for removal of heavy metals. Some organic and inorganic materials are used as adsorbents with and without pretreatment such as polymers [11], [12], zeolites [13], [14], lignite [15], waste tires [16], algae [17], crab shells [18], lignin [19], fly ash [20], [21], activated carbon from various agricultural residues [22]-[27], tree barks [8], [28]-[30] for removing various heavy metals from aqueous and waste water.

Level of toxicity affecting living forms depends on type of heavy metal ions such as lead, copper, cobalt, cadmium, chromium, nickel, mercury, arsenic, zinc, manganese etc. Different types of manufacturing processes emit varying levels and types of heavy metals in their effluent. These heavy metals in water exhibit specific damaging effects on flora and fauna if the allowable limits are exceeded [28]. Lead can take part in the biogeochemical cycles and its mobility depends strongly on its chemical form rather than total element concentration [31]. Water bodies are found to be polluted by the presence of heavy metals due to industrial and domestic activities in the surrounding area [32], [33].The present paper highlights the method for removal of lead from aqueous and waste water.

\subsection{Adsorbent Preparation}

II. MATERIALS AND METHODS

Pongamia pinnata bark was collected in the study area, Davangere, Karnataka, India. The raw bark was Sun dried for 3 days. Then the bark was dried at $80^{\circ} \mathrm{C}$ for six hours in hot air oven and cut into 2 to 3 inch pieces. Dried bark was powdered in pulverizer. The powder was washed several times with double distilled water to remove solubles, coloring matter and again dried in hot air oven at $60^{\circ} \mathrm{C}$ for 8 hours. The powdered bark was sieved (Indian Standard Sieve) and various fractions of adsorbent was separately stored in air tight containers. The particle diameter of the various sieve fractions are as in TABLE 1. 
TABLE 1

Average particle size of adsorbent analyzed by Indian standard sieves

\begin{tabular}{clc}
\hline Sl.No. & \multicolumn{1}{c}{ Sieve Size } & Average particle size $(\mu \mathrm{m})$ \\
\hline 1 & $2.36 \mathrm{~mm}-1 \mathrm{~mm}$ & 1680 \\
\hline 2 & $1 \mathrm{~mm}-600 \mu \mathrm{m}$ & 800 \\
\hline 3 & $600 \mu \mathrm{m}-300 \mu \mathrm{m}$ & 450 \\
\hline 4 & $300 \mu \mathrm{m}-150 \mu \mathrm{m}$ & 225 \\
\hline 5 & $150 \mu \mathrm{m}-75 \mu \mathrm{m}$ & 112.5 \\
\hline
\end{tabular}

\subsection{Stock Solution}

Analytical grade Lead Sulphate was used to prepare stock solution. Double distilled water was used to prepare stock solution. Solutions of required concentrations were prepared using stock solution. $0.1 \mathrm{~N} \mathrm{HCl}$ and $0.1 \mathrm{~N} \mathrm{NaOH}$ solutions were used to adjust the $\mathrm{pH}$ of the solutions. Industrial effluent (before treatment) from a local industry was collected, filtered using whatmann no.1 filter paper and stored in air tight containers.

\subsection{Batch Adsorption Studies}

Batch adsorption studies were conducted to determine the equilibrium time required to reach saturation. Adsorption kinetics were carried out using lead Sulphate solutions of 5 to $50 \mathrm{ppm}$, $\mathrm{pH}$ in the range 2 to $9,2.5$ to $10 \mathrm{~g} / \mathrm{L}$ adsorbent of average particle size $225 \mu \mathrm{m}$, a contact time up to $60 \mathrm{~min}$, constant agitation of $200 \mathrm{rpm}$ and temperature of $30^{\circ} \mathrm{C}$. The parameters were varied one at a time and samples collected at predetermined intervals, filtered, centrifuged and analyzed by Atomic Absorption Spectrophotometer (Shimadzu). The amount of lead uptake by the bark was found. All experiments were carried out in duplicate and mean values are presented. The maximum deviation was $5.0 \%$. The percentage removal of heavy metal from the solution was calculated using (1),

$\%$ Re moval $=\frac{C_{o}-C_{i}}{C_{o}} X 100$

Where $\mathrm{C}_{0}$ is initial concentration of heavy metal, $\mathrm{C}_{\mathrm{i}}$ is final concentration of heavy metal. The adsorption capacity $\mathrm{q}_{\mathrm{e}}(\mathrm{mg} / \mathrm{g})$ after reaching equilibrium was calculated using (2).

$q_{e}=\left(C_{o}-C_{e}\right) \frac{V}{W}$

Where $\mathrm{V}$ is the volume (L) of solution and $\mathrm{W}$ is the mass ( $\mathrm{g}$ ) of adsorbate used.

\section{RESULTS AND DISCUSSION}

\subsection{Characterization of Adsorbent}

A scanning electron microscope (SEM) was used to examine surface of the Pongamia pinnata bark. Fig. 1 shows the SEM photograph of the bark. The holes are cave type openings on the surface of the bark and would increase the surface area available for adsorption. TABLE 2 shows the proximate analysis of the Pongamia pinnata adsorbent used in the present study.

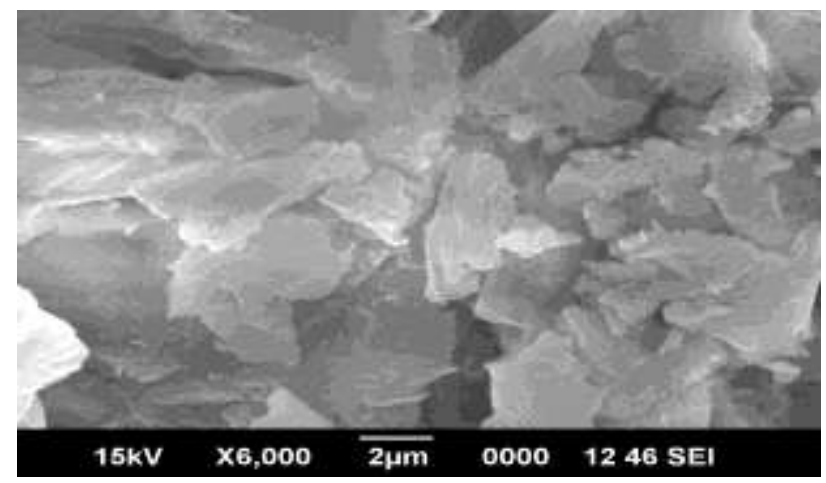

Figure.1 SEM photograph of Pongamia pinnata bark 
TABLE 2

Proximate Analysis of Pongamia pinnata Tree Bark

\begin{tabular}{clc}
\hline Sl.No. & \multicolumn{1}{c}{ Property } & Result \\
\hline 1 & Bulk density $\left(\mathrm{kg} / \mathrm{m}^{3}\right)$ & 410 \\
\hline 2 & Moisture content $(\%$ Wt. $)$ & 8.4 \\
\hline 3 & Ash content $(\% \mathrm{Wt})$. & 14.1 \\
\hline 4 & Volatile matter $(\% \mathrm{Wt})$. & 7.43 \\
\hline 5 & Fixed Carbon $(\%$ Wt. $)$ & 83.2 \\
\hline 6 & Matter soluble in water $(\%)$ & 1.51 \\
\hline 7 & Matter soluble in acid $(\%)$ & 0.56 \\
\hline
\end{tabular}

The spectral analysis of Pongamia pinnata tree bark shows the presence of 8 compounds namely, 3 -methoxy(3",4"-dihydro-3"-hydroxy-4"-acetoxy)-2",2"-dimethylpyrano-(7, 8:5",6")-flavone, 3-methoxy-(3",4"-dihydro4"-hydroxy-3"-acetoxy)-2",2"-dimethylpyrano-(7,8:5",6")-flavone, caryophyllene oxide, obovatachalcone,8hydroxy-6-methoxy-3-pentyl-1H-isochromen-1-one,6,7,2,2-dimethylchromono-8, $\gamma, \gamma,-$ dimethylallylflavanone,isolonchocarpin, ovaliflavanone A [34].

All the above mentioned compounds can be decomposed through biological degradation by various microorganisms. The decomposition products are either gases or molecules that can be recycled by other microorganisms or plants generating no negative effects on the environment. Thus the bark used for decontaminating industrial effluents can be degraded by natural means [28].

\subsection{Effect of $\mathrm{pH}$}

The effect of $\mathrm{pH}$ on the adsorption of lead is as shown in Fig.2. The $\mathrm{pH}$ of solution determines the surface charge of the adsorbent, the degree of ionization and speciation of the adsorbate. Batch equilibrium studies were carried at different $\mathrm{pH}$ values in the range of 2 to 9. It was observed from figure that maximum removal of lead ions was in the range of $\mathrm{pH} 5.0$ to 6.0. The removal of metal ions was constant above $\mathrm{pH}$ 7. This was due to the formation of metal hydroxides. This show that a strong force of interaction between the lead ions and Pongamia pinnata bark that $\mathrm{H}^{+}$ion could influence the absorption capacity. The interaction is more at $\mathrm{pH}$ 5.5 due to the competence of acidic $\mathrm{H}^{+}$ion with metal cation for the absorption sites. [24].

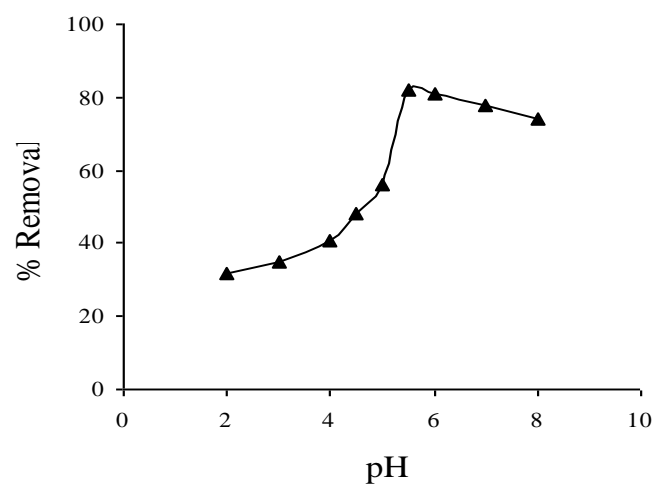

Figure. 2 Effect of $\mathrm{pH}$ on adsorption. Conditions: Initial adsorbate concentration $10 \mathrm{ppm}$; adsorbent concentration $10 \mathrm{~g} / \mathrm{L}$; contact time $1 \mathrm{hr}$; agitation $200 \mathrm{rpm}$

\subsection{Effect of Initial Metal Ion Concentration}

The effect of initial metal ion concentration is as shown in the Fig.3. From the figure it is evident that the metal uptake mechanism is dependent on initial heavy metal concentration. The metal ions are adsorbed onto the active sites of the adsorbent hence as the metal concentration increases the specific sites are saturated and no further adsorption occurs [15]. Batch experiments with varying initial metal ion concentration from $5 \mathrm{ppm}$ to 50 ppm were carried out keeping other parameters constant. It was observed that metal ion uptake was more with a solution of $5 \mathrm{ppm}$ and was observed that increase in metal ion concentration decreased adsorption. 


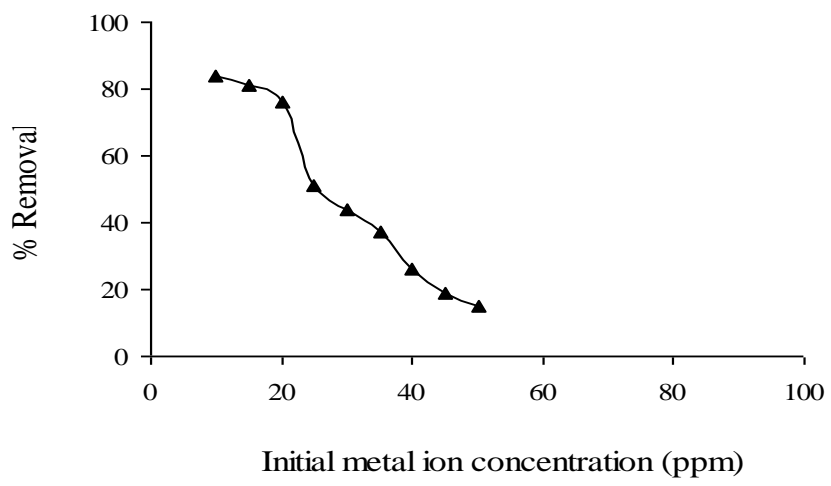

Figure. 3 Effect of Initial metal ion concentration on adsorption.

Conditions: pH 5.5; adsorbent concentration $10 \mathrm{~g} / \mathrm{L}$; contact time $1 \mathrm{hr}$; agitation $200 \mathrm{rpm}$

\subsection{Effect of Adsorbent Concentration}

As the number of active sites available for the adsorption of metal ion increases, the adsorption percentage also increases. This occurs as the concentration of adsorbent increases. In the present case, batch study with adsorbent concentration ranging between $2.5 \mathrm{~g} / \mathrm{L}$ to $10 \mathrm{~g} / \mathrm{L}$ keeping all other parameters constant was conducted. The results are as shown in Fig. 4. It shows that $10 \mathrm{~g} / \mathrm{L}$ of adsorbent concentration adsorbs the maximum metal ion in both cases.

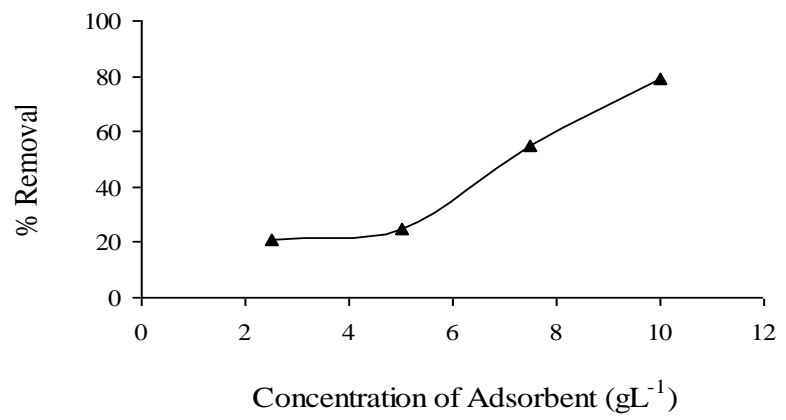

Figure.4 Effect of concentration of adsorbent on adsorption. Conditions: $\mathrm{pH}$ 5.5; Initial adsorbate concentration $10 \mathrm{ppm}$; contact time 1hr; agitation $200 \mathrm{rpm}$

\subsection{Effect of Contact Time}

The removal of lead ions from the stock solution increases with time and attains equilibrium value in about 60 to $65 \mathrm{~min}$. Initially within 20 to $40 \mathrm{~min}$ the uptake of metal ions from bark is rapid, but gradually decreases with time till it reaches equilibrium. In the beginning the number of active sites available for adsorption is more hence metal uptake increases but later on the available active sites reduce and metal ions need to compete for the vacant sites. Fig. 5 shows that at the start of the adsorption the percent removal of metal ions is more and later reaches a constant value where upon no further adsorption was observed.

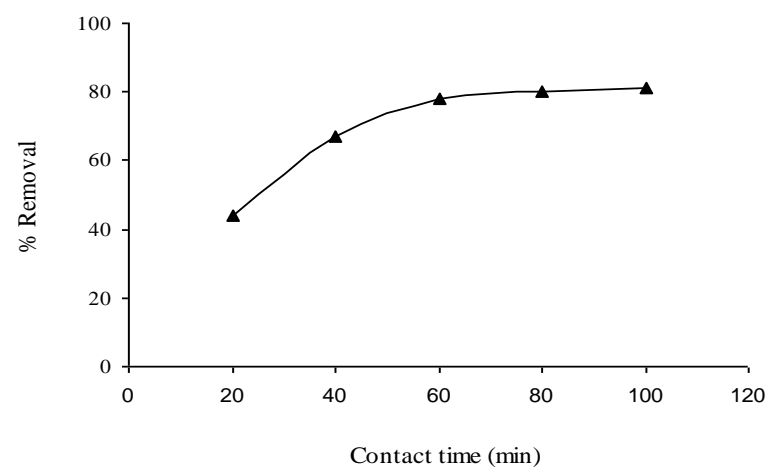

Figure.5 Effect of contact time on adsorption. Conditions: Initial adsorbate concentration 10 ppm; adsorbent concentration $10 \mathrm{~g} / \mathrm{L}$; $\mathrm{pH}$ 5.5; agitation $200 \mathrm{rpm}$ 


\subsection{Adsorption Isotherms}

From all the batch experiments carried out optimum parameters selected were $\mathrm{pH}$ of 5.5, initial metal ion concentration of $10 \mathrm{ppm}$, adsorbent concentration of $10 \mathrm{~g} / \mathrm{L}$, contact time of 10 to $60 \mathrm{~min}$, temperature of $30^{\circ}$ $\mathrm{C}$ and agitation of $200 \mathrm{rpm}$. The adsorption data was correlated with the Langmuir and the Freundlich isotherm model equations.

The Langmuir isotherm is valid for monolayer adsorption onto a surface with a finite number of identical sites. It is based on assumption of adsorption homogeneity, such as equally available adsorption sites, monolayer surface coverage and no interaction between adsorbed species [8]. According to the Langmuir adsorption isotherm, the adsorption process can be expressed as (3)

$q_{e}=\frac{q_{m} C_{e}}{K_{d}+C_{e}}$

On rearrangement of (3) to linear form as (4)

$$
\frac{C_{e}}{q_{e}}=\frac{C_{e}}{q_{m}}+\frac{K_{d}}{q_{m}}
$$

Where $\mathrm{C}_{\mathrm{e}}(\mathrm{mg} / \mathrm{L})$ is the equilibrium concentration of lead ions in solution, $\mathrm{q}_{\mathrm{e}}(\mathrm{mg} / \mathrm{g})$ the adsorption capacity at equilibrium, $\mathrm{q}_{\mathrm{m}}(\mathrm{mg} / \mathrm{g})$ the maximum adsorption capacity and $\mathrm{K}_{\mathrm{d}}$ is the effective dissociation constant. The values of $\mathrm{q}_{\mathrm{m}}$ and $\mathrm{K}_{\mathrm{d}}$ estimated from the Fig.6 for adsorption of lead were $15.3 \mathrm{mg} / \mathrm{g}$ and 5.7 respectively. The correlation coefficient of the Langmuir isotherm $\left(\mathrm{R}^{2}\right)$ was 0.9967.

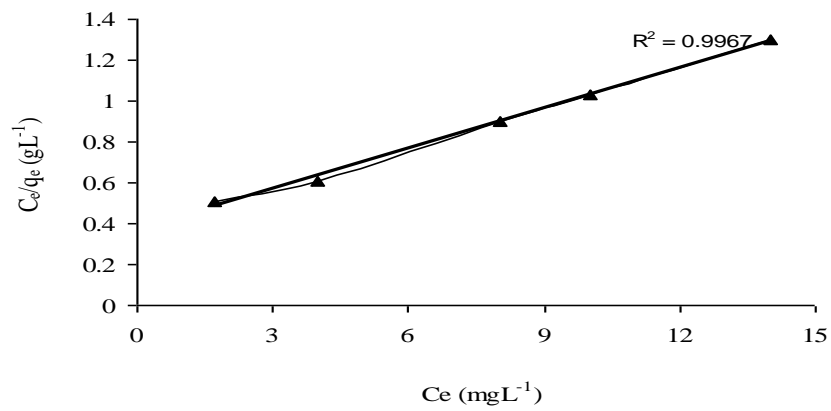

Figure.6 Langmuir adsorption isotherm of lead ion in aqueous solution.

In the Freundlich equation, the empirical relationship whereby it is assumed that the adsorption energy of lead ions binding to a site on an adsorbent depends on the adjacent sites available for adsorption and it is a multilayer adsorption process. The Freundlich isotherm is expressed as (5)

$q_{e}=k_{f}\left(C_{e}\right)^{\frac{1}{n}}$

On rearrangement to linear form (6)

$\ln q_{e}=\ln K_{f}+\frac{1}{n} C_{e}$

Where $\mathrm{q}_{\mathrm{e}}(\mathrm{mg} / \mathrm{g})$ is the adsorption capacity at equilibrium, $\mathrm{C}_{\mathrm{e}}(\mathrm{mg} / \mathrm{L})$ the equilibrium concentration of lead ions in solution, $\mathrm{K}_{\mathrm{f}}$ and $\mathrm{n}$ are the physical constants of the Freundlich adsorption isotherm. The $\mathrm{K}_{\mathrm{f}}$ and $\mathrm{n}$ values are the indicators of the adsorption capacity and adsorption intensity respectively. The slope and the intercept of the linear Freundlich equation are equal to $1 / \mathrm{n}$ and $\ln \mathrm{K}_{\mathrm{f}}$ respectively as in Fig.7. The constants $\mathrm{n}$ and $\mathrm{K}_{\mathrm{f}}$ obtained from Fig.7 were 2.04 and 3.07 respectively. The correlation coefficient of the Freundlich isotherm $\left(\mathrm{R}^{2}\right)$ was 0.9856 .

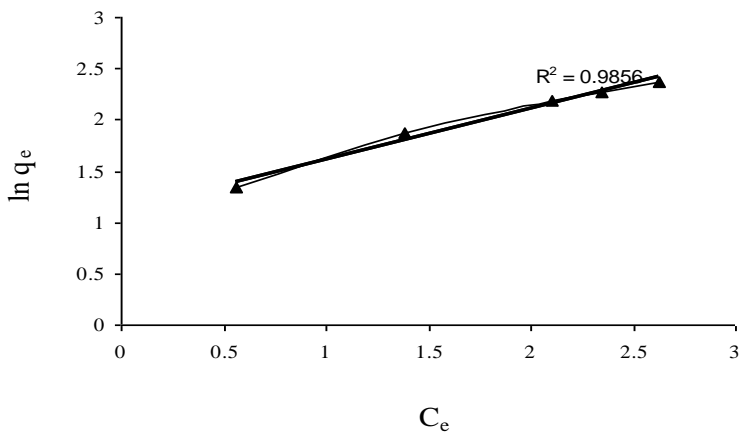

Figure.7 Freundlich adsorption isotherm of lead ion in aqueous solution. 
Comparing both of the correlation coefficients obtained, it shows that the Langmuir isotherms suits well for the obtained adsorption data than Freundlich isotherm.

\subsection{Adsorption Kinetics}

The kinetics involved in the adsorption of lead ions on to Pongamia pinnata were studied based on three models namely, the pseudo first order, pseudo second order and Elovich model. For the adsorption of solute from liquid solutions, pseudo first order model is most widely used. This model is as below, $\ln \left(q_{e}-q_{t}\right)=\ln q_{e}-K_{1} t$

Where $\mathrm{q}_{\mathrm{e}}$ is the mass of metal ion adsorbed at equilibrium $(\mathrm{mg} / \mathrm{g}), \mathrm{q}_{\mathrm{t}}$ is the mass of metal adsorbed at time $\mathrm{t}(\mathrm{mg} / \mathrm{g}), \mathrm{K}_{1}$ is the first order reaction rate constant $\left(\mathrm{min}^{-1}\right)$. Plot of $\ln \left(\mathrm{q}_{\mathrm{e}}-\mathrm{q}_{\mathrm{t}}\right)$ vs. $\mathrm{t}$ indicates the application of the first-order kinetic model as shown in Fig. 8.

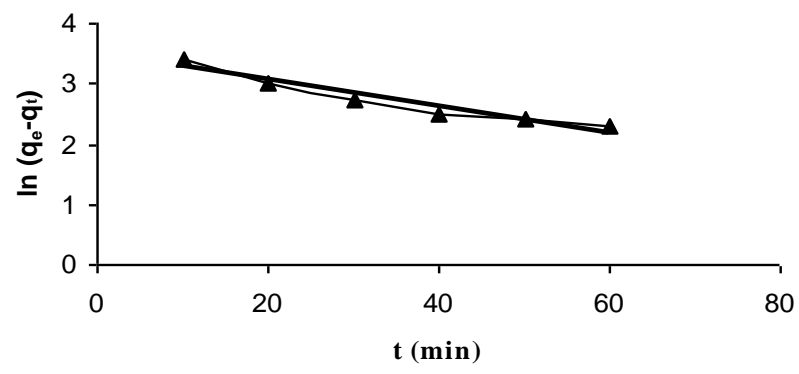

Figure.8 First order kinetic model for lead ion adsorption.

Based on equilibrium adsorption capacity pseudo second order model is as shown in the form

$\frac{t}{q_{t}}=\frac{1}{K_{2} q_{e}^{2}}+\frac{t}{q_{e}}$ linear relation for the second order kinetics to be applicable to that model as shown in Fig. 9.

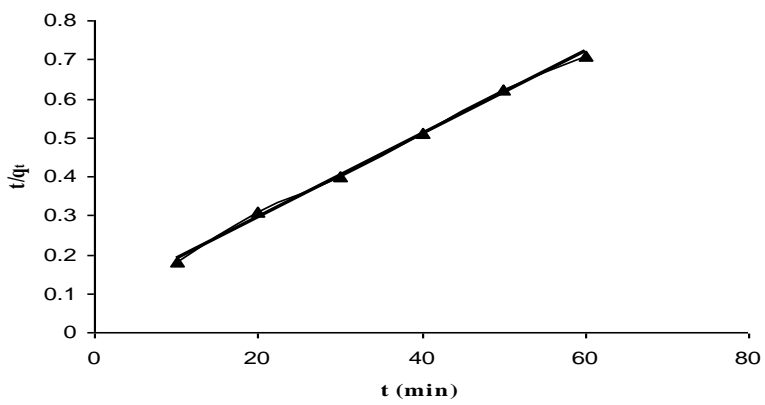

Figure.9 Second order kinetic model for lead ion adsorption.

Elovich model for the adsorption is expressed as

$q_{t}=\alpha+\beta \ln t$

A plot of $\mathrm{q}_{\mathrm{t}}$ against $\ln \mathrm{t}$ gives a linear relationship for the applicability of the simple Elovich kinetic model as shown in Fig.10.

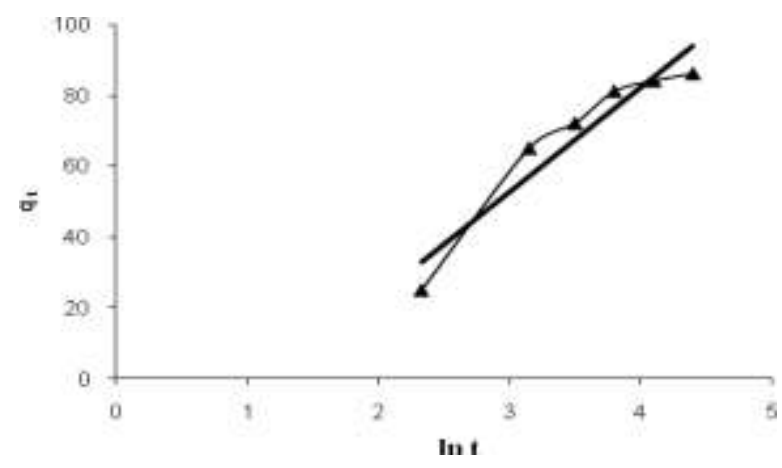

Figure.10 Elovich kinetic model for lead ion adsorption. 
Comparing all the above models the parameters obtained are reported in TABLE 3. Based on linear regression $\left(\mathrm{R}^{2}>0.99\right)$ values, the kinetics of lead ion adsorption on Pongamia pinnata can be described well by pseudo second order kinetics.

TABLE 3

Parameters of Kinetic models

\begin{tabular}{|c|c|c|c|c|c|c|c|}
\hline \multirow[t]{2}{*}{ Metal ion } & \multicolumn{2}{|c|}{ First order } & \multicolumn{2}{|c|}{ Second order } & \multicolumn{3}{|c|}{ Elovich } \\
\hline & $\overline{\mathrm{R}^{2}}$ & $\mathrm{~K}_{1}$ & $\mathrm{R}^{2}$ & $\mathrm{~K}_{2}$ & $\mathrm{R}^{2}$ & $\alpha$ & $\beta$ \\
\hline Lead & 0.9353 & 0.02 & 0.9975 & $1.31 \times 10^{-3}$ & 0.91 & -35.85 & 29.517 \\
\hline
\end{tabular}

\subsection{Mechanism of Adsorption}

The mechanism of adsorption of metal ion onto adsorbent follows three steps viz. the movement of metal ion from bulk liquid onto the surface of adsorbent, pore diffusion and intra particle transport. The overall rate of the adsorption is governed by the slowest step of all. For the batch adsorption mode, pore and intra particle diffusion are rate limiting whereas in case of continuous adsorption mode, film diffusion is more likely the rate limiting step. The adsorption rate parameter which controls the batch process for most of the contact time is intra particle diffusion. The possibility of intra particle diffusion resistance affecting adsorption was explored by using the intra particle diffusion model as

$q_{t}=k_{i} t^{1 / 2}+I$

Where, $k_{i}$ is the intra particle diffusion rate constant, a plot of $q_{t} v s . t_{1 / 2}$ for lead ions is as shown in Fig. 11. Values of I are as reported in TABLE 4. I values give an idea about the thickness of boundary layer. The larger the intercept the greater is the boundary layer effect.

TABLE 4

Kinetic Parameters and Boundary layer for adsorption

\begin{tabular}{lccc}
\hline Metal ion. & $\mathrm{k}_{\mathrm{i}}$ & $\mathrm{I}$ & $\mathrm{R}^{2}$ \\
\hline Lead & 10.69 & 0.71 & 0.988 \\
\hline
\end{tabular}

The deviation of straight lines from the origin as shown in the Fig.11 may be because of the difference between the rate of mass transfer in the initial and final steps of adsorption. Further, such deviation of straight line from the origin indicates that the pore diffusion is not the rate controlling step.

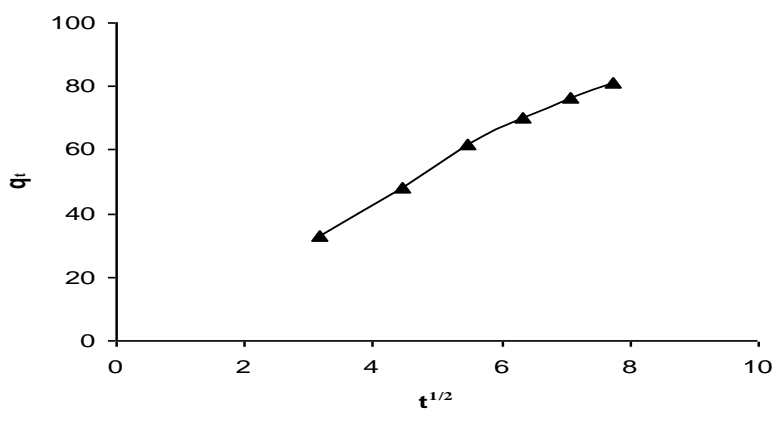

Figure.11 Mechanism of particle diffusion for lead ion adsorption.

From Fig.11, it may be seen that there are two separate regions the first portion is attributed to the bulk diffusion and second portion to the intraparticle diffusion. The values of $\mathrm{k}_{\mathrm{i}}, 1$ and $\mathrm{k}_{\mathrm{i}}, 2$ are obtained from slopes of the two straight lines are 12.47 and 7.76 respectively.

\subsection{Adsorption of Lead from Industrial Effluent}

Raw industrial effluent without treatment was collected from a local wire drawing industry. After filtration, batch experiments were carried out using $100 \mathrm{ml}$ of effluent each with $10 \mathrm{~g} / \mathrm{L}$ adsorbent, temperature of $30^{\circ} \mathrm{C}$ and agitation of $200 \mathrm{rpm}$. The $\mathrm{pH}$ of solution was varied from 2 to 7 . Fig. 12 shows the effect of $\mathrm{pH}$ on the adsorption of lead by Pongamia pinnata bark. Maximum removal of lead was observed in the $\mathrm{pH}$ range 5 to 6 which was in agreement with the aqueous solution. The maximum adsorption was found to be $34.36 \mathrm{mg} / \mathrm{g}$ in effluent at a temperature of $30^{\circ} \mathrm{C}$. The percentage lead removal was interfered as the effluent consisted of other competing ions such as copper, iron and nickel. 


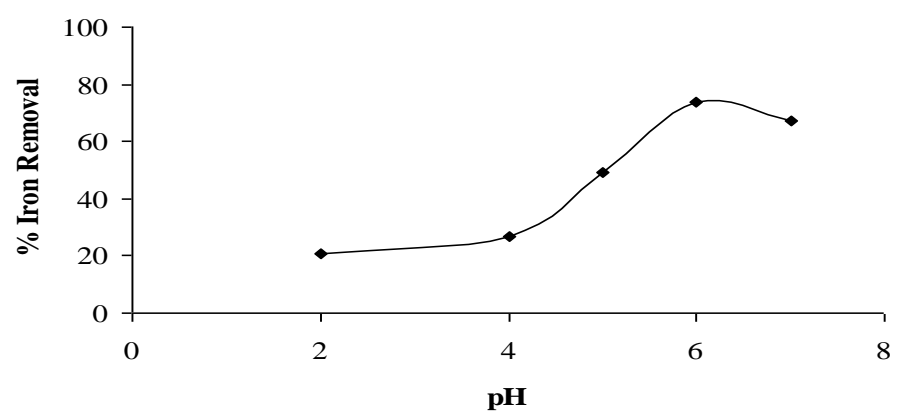

Figure.12 Effect of $\mathrm{pH}$ on adsorption of lead from industrial effluent.

Conditions: adsorbent concentration $10 \mathrm{~g} / \mathrm{L}$; contact time $1 \mathrm{hr}$; agitation $200 \mathrm{rpm}$.

\section{CONCLUSION}

Pongamia pinnata seeds are widely used for biofuel production, hence in recent years this tree is widely grown in the fields. Thus the availability of the Pongamia pinnata tree bark is more. Also the adsorbent preparation does not involve the activation process of the bark hence the preparation is simple and economical. It was concluded from the present study that Pongamia pinnata tree bark can be used effectively for the removal of lead from aqueous and industrial effluents. The adsorption data were better fitted by Langmuir model than Freundlich isotherm model. An optimum of 5 to $6 \mathrm{pH}, 10 \mathrm{~g} / \mathrm{L}$ of adsorbent, initial metal ion concentration of $10 \mathrm{ppm}$, with a contact time of $60 \mathrm{~min}$ and agitation 200rpm was chosen from the experiments conducted. Pseudo second order model best fitted the kinetics. In case of industrial effluent, the decrease in the percent removal of lead was due to the interference of other metal ions present. In this regard, Pongamia pinnata tree bark can be effectively used as a viable and economic adsorbent for removal of lead from aqueous and industrial effluents.

\section{ACKNOWLEDGMENT}

The authors thank the management of Bapuji Institute of Engineering and Technology, Davangere for providing the necessary facilities to undertake the above work.

\section{REFERENCES}

[1] G.Nabulo, C. R.Black, S.D.Young, Trace metal uptake by tropical vegetables grown on soil amended with urban sewage sludge, Environmental Pollution, 159 (2), 2011, 368-376.

[2] Safia A Cavaco, Sandra Fernandes, Margarida M Quina, Licinio M. Ferreira, Removal of chromium from electroplating industry effluents by ion exchange resins, Journal of Hazardous Materials, 144, 2007, 634-638.

[3] L.Koene, L.J.J.Janseen, Removal of nickel from industrial process liquids, Electrochimica acta, 47, 2001, 695-703.

[4] ISI, Tolerance limits for industrial effluents prescribed by Indian Standard Institution, IS: 2490 (part I) 1982.

[5] B.M. Kim, P.A. Amodeo, Calcium sulphide process for treatment of metal containing wastes, Environmental Progress, 2, 1983, 175-180.

[6] Mohamed Kheireddine Arova, S.P.P. Leong, L.Y.Teo, Chun Yang Yin, Wan Mohd Ashri Wan Daud, Real time determination of kinetics of adsorption of lead (II) onto palm shell-based activated carbon using ion selective electrode, Bioresource Technology, 99, 2008, 5786-5792.

[7] F.Hassaine-sadi, L.Sadoun, Treatment of industrial wastes containing toxic metals (Chromium), Purification by liquid membranes, Desalination, 185, 2005, 335-340.

[8] Diwakar Tiwari, Hyoung-Uk Kim, Seung-Mok Lee, Removal behavior of Sericite for $\mathrm{Cu}(\mathrm{II})$ and $\mathrm{Pb}$ (II) from aqueous solutions: Batch and column studies, Separation and Purification Technology, 57, 2007, 11-16.

[9] A.L, Zouboulis, A, Mastisk. Removal of metal ions from dilute solutions by sorption flotation, Critical review in Environmental, 1997, 195-235.

[10] Virendra Kumar Mishra, B.D.Tripathi, Concurrent removal and accumulation of heavy metals by the three aquatic macrophytes, Bioresource Technology. 99, 2008, 7091-7097.

[11] J.Deans, B. Dixon, Uptake of $\mathrm{Pb}^{2+}$ and $\mathrm{Cu}^{2+}$ by novel biopolymers, Water Research, 26, 1992, 469-472.

[12] Gregorio Crini, Recent developments in polysaccharide-based materials used as adsorbents in waste water treatment, Progress in Polymer Science, 30, 2005, 38-70.

[13] Babel. S, Kurniawan T.A, Chromium removal from electroplating waste water using chemically treated zeolite, Proceedings of the $9^{\text {th }}$ world Filtration Congress, 18-22, April, New Orleans, USA, 2004, 1-14.

[14] Ali Hakan Oren, Abidin Kaya, Factors affecting adsorption characteristics of $\mathrm{Zn}^{2+}$ on two natural zeolites, Journal of Hazardous Materials B131, 2006, 59-65.

[15] Dinesh Mohan, Subhash Chander, Removal and recovery of Metal ions from acid mine drainage using lignite, A low cost sorbent, Journal of Hazardous Materials, B137, 2006, 1545-1553.

[16] G. Skodras, Ir.Diamantopoulou, A.Zabaniotou, G.Stavropoulos, G.P.Sakellaropoulas, Enhanced mercury adsorption in activated carbons from biomass materials and waste tires, Fuel Processing Technology, 88, 2007, 749-758.

[17] Donmez.G.C, Aksu.Z, Ozturk.A, Kutsal.T, A comparative study on heavy metal biosorption characteristics of some algae, Process Biochemistry, 34, 1997, 885-892.

[18] Swapna Pradhan, Shyam. S. Shukla, Kenneth L Dorris, Removal of nickel from aqueous solutions using crab shells Journal of Hazardous Materials, B 125, 2005201-204. 
[19] Dinesh Mohan, Charles U. Pittman Jr, Philip H. Steele, Single, binary and multi- component adsorption of copper and cadmium from aqueous solutions on kraft lignin-a biosorbent, Journal of Colloid Interface Science, 297, 2006, 489-504.

[20] Shaobin Wang, T.Terdkiatburana, M.O.Tade, Single and Co-adsorption of heavy metals and humic acid on fly ash, Separation and Purification Technology, 58 (3), 2008, 353-358.

[21] Heechan Cho, Dalyoung Oh, Kwanho Kim, A study on removal characteristics of heavy metals from aqueous solution by fly ash, Journal of Hazardous Materials. B127, 9, 2005, 187- 195.

[22] S.K.Banerjee, M.D.Mathew, Carbonization of jute, an agricultural waste, Agricultural waste, 15, 1985, 225-229.

[23] D.Mohan, K.P.Singh, Single and Multicomponent adsorption of cadmium and zinc using activated carbon derivated from bagassean agricultural waste, Water Research, 36, 2002, 2304- 2318.

[24] Harshala Parab, Shreeram Joshi, Niyoti shenoy, Arvind Lali, U.S.Sarma, M. Sudersanan, Determination of kinetic and equilibrium parameters of the batch adsorption of $\mathrm{Co}(\mathrm{II}), \mathrm{Cr}(\mathrm{III})$ and Ni(II) onto coir pith, Process Biochemistry, 41, 2006, 609-615.

[25] C.Namasivayam, D.Sangeetha, Recycling of agricultural solid waste, coir pith: Removal of anions, heavy metals, organics and dyes from water by adsorption onto $\mathrm{ZnCl}_{2}$ activated coir pith carbon, Journal of Hazardous Materials, B 135, $2006,449-452$.

[26] Dinesh Mohan, Kunwar P.Singh, Vinod K. Singh, Trivalent Chromium removal from waste water using low cost activated carbon derived from agricultural waste material and activated carbon fabric cloth Journal of Hazardous Materials, B135, $2006,280-295$.

[27] K.Kadirvelu, M. Kavipriya, C.Karthika, M. Radhika, N. Vennilamani, S. Pattabhi, Utilization of various agricultural wastes for activated carbon preparation and application for the removal of dyes and metal ions from aqueous solutions, Bioresource Technology, 87, 2003, 129-132.

[28] I. Gaballah, G. Kilbertus, Recovery of heavy metal ions through decontamination of synthetic solutions and industrial effluents using modified barks. Journal Geochemical Exploration, 62, 1998, 241-286.

[29] B. R.Reddy, N.Mirghaffari, I.Gaballah, Removal and recycling of copper from aqueous solutions using treated Indian barks, Resources Conservation Recycling, 21, 1997, 227-245.

[30] E. Nehrenheim, J. P. Gustafsson, Kinetic sorption modelling of $\mathrm{Cu}, \mathrm{Ni}, \mathrm{Zn}, \mathrm{Pb}$ and $\mathrm{Cr}$ ions to pine bark and blast furnace slag by using batch experiments, Bioresource Technology, 99, (6), 2008, 1571-1577.

[31] Garcia, G., Zanuzzi, A.L., Faz, A. Evaluation of heavy metal availability prior to an in situ soil phytoremediation program. Biodegradation 16, 2005,187-194.

[32] J.U.Deshmukh, E. Ambore, J. S. Pulle, Heavy metal Pollution of Godvari River due to industrial effluents from M.I.D.C Nanded, Maharastra, India, Journal of Industrial Pollution Control, 23(1), 2007, 107-111.

[33] R. Ramesh, R. Purvaja, S. Ramesh, R. A. James, Historical pollution trends in coastal environments of India, Environmental Monitoring and Assessment, 79, 2002, 151-176.

[34] Y N Hao, Zhang Si, Jun Wu and Nan Haihan,, Dihydropyranoflavones from Pongamia pinnata, Journal of the Brazilian Chemical Society, 17, 2006, 1432-1435. 